\title{
Separation of Lutidine Isomers by Selective Enclathration
}

\author{
Jacky S. Bouanga Boudiombo ${ }^{1}$, Hong Su${ }^{1}$, Neil Ravenscroft ${ }^{1}$, Susan A. Bourne ${ }^{1}$, Edwin Weber ${ }^{2}$, \\ and Luigi R. Nassimbenia ${ }^{1}$
}

${ }^{1}$ Centre for Supramolecular Chemistry Research, Department of Chemistry, University of Cape Town, Rondebosch 7701, SouthAfrica, ${ }_{2}^{2}$ Institut für Organische Chemie, TU Bergakademie Freiberg, Leipziger Straße 29, D-09596 Freiberg/Sachs, Germany

*luigi.nassimbeni@uct.ac.za

Molecular selectivity by host-guest procedures is an increasing method to help in the separation of isomers ${ }^{1}$. The separation of a component from a mixture may be carried out by exploiting the physico-chemical properties of the compounds in that mixture. The most common techniques, viz. distillation, crystallization, liquid-liquid extraction, and various forms of chromatography, rely on differences in solubility and vapor pressure of the components. In the case of molecular isomers, however, their macro-properties are often similar, rendering the traditional separation techniques inefficient. In such cases the process of enclathration by a suitable host compound is a useful technique. ${ }^{2,3,4}$

In this study, the host compound 3,3'-bis(9-hydroxy-9-fluorenyl)-2-2'-binaphthyl, H1, has been employed to separate the six isomers of lutidine. Competition experiments showed that the preference for enclathration is in the sequence 3,4-LUT $>2,6-$ LUT $>2,3$-LUT $>2,5$-LUT $>2,4$-LUT $\approx 3,5$-LUT. The structures yielded results that agree with the $1 \mathrm{H}$ NMR analyses and with the thermal analysis. The effects of mixed hosts and vapor-phase competitions were briefly explored with two extra hosts, namely, 2,2'-bis(1-hydroxy-4,5-dihydro-2:3,6:7dibenzocycloheptadien-1-yl)biphenyl(H2) or 3,3'-bis(di-p-olylhydroxymethyl) -1,1'-binaphthyl (H3). Following this study, 2,2'bis(1hydroxy-4,5-dihydro-2,3:6,7-dibenzocycloheptatrien-1-yl)-biphenyl, $\mathrm{H} 2$, was then employed to discriminate between all the pairs of lutidine isomers. The preference for guest enclathration follows the sequence 3,4-LUT>2,4-LUT $\approx 3,5-\mathrm{LUT}>2,5-\mathrm{LUT}>2,3-\mathrm{LUT}>2,6-\mathrm{LUT}$. This has been confirmed by guest-release endotherms measured by DSC. Four extra diol host compounds with similar structures were tested on pairs of lutidine isomers which were poorly separated by $\mathrm{H} 2$.

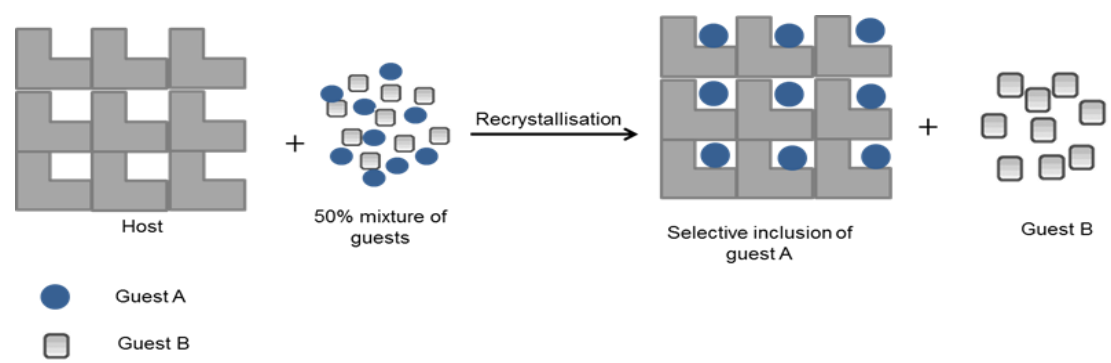

Figure 1. Molecular chemistry by host-guest chemistry.

\section{Keywords: Dio-hosts, separation, lutidine isomers}

[1] Nassimbeni, L. R. In Separations and Reactions in Organic Supramolecular Chemistry; Toda, F., Bishop, R., Eds.; Wiley: Chichester, 2004; Chapter 5.

[2] Yang,Y., Bai, P., Guo, X., Separation of xylene isomers: a review of recent advances in materials Ind. Eng. Chem. Res., 56 (2017), pp. $14725-$

14753.

[3] B. Barton, E.C., Hosten, P.L., (2016) Tetrahedron, 72, 8099-8105.

[4] Nassimbeni, L.R., Bathori, N.B., Patel, L.D., Su, H. \& Weber E. (2015) Chem. Commun., 51, 3627-3629. 